\title{
Significance of antibodies to cytoplasmic components of neutrophils
}

Serum antibodies against cytoplasmic components of neutrophils were described in patients with segmental necrotising glomerulonephritis by Davies and others in $1982^{1}$ and by Hall and associates in $1984 .^{2}$ Van der Woude and associates ${ }^{3}$ recognised the relation of these antibodies to Wegener's granulomatosis and their potential for monitoring activity of the disease, findings that were confirmed by Gross and others. ${ }^{45}$

The report of Harrison and colleagues in this issue is important for two reasons. Firstly, it emphasises the importance of attention to detail in the methods and of differentiating between the various fluorescence patterns that may be encountered when the indirect immunofluorescence technique is used for detecting and quantifying anticytoplasmic autoantibodies. Secondly, it confirms once more their high specificity for Wegener's granulomatosis and microscopic polyarteritis as well as their value for following disease activity.

According to the conclusions from the first international workshop on ANCA, ${ }^{6}$ the abbreviation ANCA (for antineutrophil cytoplasmic antibodies) should be used only for serum antibodies causing the characteristic granular, centrally accentuated, cytoplasmic fluorescence pattern on ethanol fixed neutrophil cytospin or smear preparations. In that sense it is synonymous with the acronym ACPA (for anticytoplasmic antibodies) used in the initial reports relating autoantibodies to cytoplasmic components of neutrophils and monocytes to Wegener's granulomatosis. ${ }^{3-5}$ The ACPA/ANCA pattern needs to be distinguished from non-specific perinuclear cytoplasmic and nuclear fluorescence patterns, which may be encountered in various other vasculitides and forms of connective tissue disease ${ }^{67}$ Harrison and his colleagues show very nicely how the specificity of ACPA/ANCA depends on strict adherence to this definition.

The authors also noted that the granularity of the fluorescence decreases with increasing serum dilution. They usually detected the phenomenon of transition from the granular to a more diffuse fluorescence pattern at dilutions of 1:160, though in our experience this phenomenon is occasionally encountered at dilutions as low as 1:8. This is one of the reasons why we, following the method used by Gross and associates, ${ }^{5}$

Address for reprint requests: Professor Richard A DeRemee, Mayo Medical School, Rochester, Minnesota 55905, USA. screen for ACPA/ANCA using undiluted serum as well as a dilution of 1:4. If the characteristic granular pattern is not detectable on these screening slides the sample is considered to be ACPA/ANCA negative. Brightness of fluorescence is of secondary importance. The final titre levels are determined where the central accentuation of the fluorescence disappears - that is, just before the serum dilution that can no longer be distinguished from the phosphate buffered saline control slide also included in each assay run. A granular fluorescence pattern must be seen at least on the lowest dilution slide used for screening for the serum sample to be called ACPA/ANCA positive.

Harrison and associates also show why it is essential to comply with the standardised ethanol fixation method. Neither acetone nor formalin-acetone fixation allows the distinction between ACPA/ANCA and other antibodies, which may be directed in part against myeloperoxidase. $^{8}$

Lockwood and associates reported the presence of ANCA in serum from patients with microscopic polyarteritis. ${ }^{9}$ In these patients sera generated a diffuse non-granular fluorescence pattern, whereas the sera from our patients with microscopic polyarteritis ${ }^{7}$ and those reported by Lüdemann and others ${ }^{10}$ have shown the characteristic granular ACPA/ANCA pattern. Interestingly, Harrison et al also found that sera from some patients with microscopic polyarteritis generated the characteristic ACPA/ANCA pattern. Microscopic polyarteritis is a form of necrotising small vessel vasculitis that shares many clinical features with both Wegener's granulomatosis and classic polyarteritis nodosa, though lacking some salient features of both." The only histopathological distinction between microscopic polyarteritis and Wegener's granulomatosis is the presence of granulomas and the frequent occurrence of venulitis in the latter. The detection of ACPA/ANCA in microscopic polyarteritis is therefore important, because it represents another link between the two diseases and suggests that a common pathogenetic mechanism might underlie microscopic polyarteritis and Wegener's granulomatosis.

Harrison and associates found the characteristic ACPA/ANCA fluorescence pattern in one patient with Churg-Strauss syndrome. We have tested only two patients with clinically active, biopsy proved 
Churg-Strauss syndrome and serum from both was ACPA/ANCA negative.' A larger number of active, clinically clear cut, and biopsy proved Churg-Strauss cases will need to be tested to determine whether the syndrome does indeed represent another entity in which ACPA/ANCA may be present.

Given their high specificity, ACPA/ANCA have the potential to allow an earlier diagnosis of Wegener's granulomatosis, and to increase our understanding of the range of clinical manifestations of this disease. ${ }^{12}$ Although a positive ACPA/ANCA test result cannot at this point replace the aggressive pursuit of a tissue diagnosis, it may be helpful in cases in which for various reasons a tissue diagnosis cannot be obtained. ${ }^{13}$ In most instances Wegener's granulomatosis manifests itself first in the respiratory tract but kidney lesions may precede other organ manifestations. ${ }^{14}$ is The presence of ACPA/ANCA in such cases might allow an early distinction between "limited Wegener's granulomatosis of the kidney" and glomerulonephritides of a different nature.

It seems incredible that ACPA/ANCA should be so specific. Yet repeated studies continue to confirm the phenomenon. Some confusion has been introduced by regarding all fluorescence in the cytoplasm of neutrophils as equivalent. This is decidedly not true. Whereas homogeneous and perinuclear fluorescence are technically cytoplasmic in origin, it is the distinct granular pattern that we should look for in relation to Wegener's granulomatosis or microscopic polyarteritis. It appears therefore that semantics have been in the last analysis the problem and root of confusion. This logically raises the question of whether we should develop a new nomenclature with more specific meanings.

To what degree ACPA/ANCA represent the key to a better understanding of the pathogenetic mechanisms operating in Wegener's granulomatosis and microscopic polyarteritis will ultimately depend on the characterisation of the corresponding antigen or antigens. Here the only data to have been reported are very conflicting. ${ }^{89}$ 16-18

ULRICH SPECKS

RICHARD A DEREMEE

Thoracic Diseases and Internal Medicine Mayo Clinic

Rochester, Minnesota 55905, USA

\section{References}

1 Davies DJ, Moran JE, Niall JF, Ryan GB. Segmental necrotising glomerulonephritis with antineutrophil antibody: possible arbovirus aetiology? $\mathrm{Br} \mathrm{Med} J 1982$; 285:606.

2 Hall JB, Wadham BM, Wood CJ, Ashton V, Adam WR. Vasculitis and glomerulonephritis: a subgroup with an antineutrophil cytoplasmic antibody. Aus NZ J Med 1984;14:277-8.
3 Van der Woude FJ, Rasmussen $\mathrm{N}$, Lobatto $\mathrm{S}$, et al. $\stackrel{\times}{-}$ Autoantibodies against neutrophils and monocytes: $\overrightarrow{\overline{\vec{S}}}$ tool for diagnosis and marker of disease activity in - Wegener's granulomatosis. Lancet 1985;i:425-9.

4 Gross WL, Lüdemann G, Kiefer G, Lehmann H. Anticytoplasmic antibodies in Wegener's granu- $\frac{\rho}{\partial}$ lomatosis [letter]. Lancet 1986;i:806.

5 Lüdemann G, Gross WL. Autoantibodies against cyto- D plasmic structures of neutrophil granulocytes in Wegener's granulomatosis. Clin Exp Immunol 1987;69: . 350-7.

6 Rasmussen N, Wiik A, Høier-Madsen M, Borregaard N, van der Woude F. Anti-neutrophil cytoplasm antibodies 1988. Lancet 1988;i:706-7.

7 Specks U, Wheatley CL, McDonald TJ, Rohrbach MS, $\stackrel{\vec{A}}{\vec{A}}$ DeRemee RA. Anticytoplasmic autoantibodies in the or diagnosis and follow-up of Wegener's granulomatosis. $\omega$ Mayo Clin Proc 1989;64:28-36.

8 Falk RJ, Jennette JC. Anti-neutrophil cytoplasmic autoantibodies with specificity for myeloperoxidase in patients with systemic vasculitis and idiopathic $\vec{z}$ necrotizing and crescentic glomerulonephritis. $N$ Engl J Med 1988;318:1651-7.

9 Lockwood CM, Bakes D, Jones S, Whitaker KB, Moss $\overrightarrow{0}$ DW, Savage COS. Association of alkaline phosphatase with an autoantigen recognised by circulating antineutrophil antibodies in systemic vasculitis. Lancet 1987;i:716-20.

10 Lüdemann G, Nölle B, Rautmann A, Rosenboom S, $\overline{\bar{O}}$ Kekow J, Gross WL. Antizytoplasmatische Antikör- 응 per als Seromarker und Aktivitätsparameter der $\stackrel{\mathbb{Q}}{\varrho}$ Wegenerschen Granulomatose. Disch Med Wochen- $\overrightarrow{\vec{B}}$ schr 1988;113:413-7.

11 Savage COS, Winearls CG, Evans DJ, Rees AJ, Lockwood CM. Microscopic polyarteritis: presentation, $\frac{\vec{F}}{0}$ pathology and prognosis. $Q J$ Med 1985;56:467-83.

12 Specks U, DeReeme RA. Do anticytoplasmic autoantibodies (ACPA) extend our understanding of the spec- 음 trum of Wegener's granulomatosis? Prax Klin Pneumol $\times$ (in press).

13 Parlevliet KJ, Henzen-Logmans SC, Oe PL, Bronsveld W, Balm AJM, Donker AJM. Antibodies to compo- § nents of neutrophil cytoplasm: a new diagnostic tool in $३$ patients with Wegener's granulomatosis and systemic 0 vasculitis. $Q J$ Med 1988;66:55-63.

14 Woodworth TG, Abuelo JG, Austin III HA, Esparza A. $\frac{D}{O}$ Severe glomerulonephritis with late emergence of classic Wegener's granulomatosis. Medicine (Baltimore) $\mathrm{N}$ 1987;66:181-91.

15 Oliet A, Praga M, Vidaur F, Elósegui A, Usera G, Bello I. 응 Periglomerular granulomatosis. A limited form of $\mathbf{\omega}$ Wegener's granulomatosis with exclusive renal $\sigma$ involvement? Arch Intern Med 1988;148:1377-9.

16 Rasmussen N, Borregard N, Wiik A. Anti-neutrophilcytoplasm antibodies in Wegener's granulomatosis are $\mathbb{D}$ not directed against alkaline phosphatase. Lancet 1987;i:1488.

17 Gross WL, Lüdemann J, Schröder JM. Anti-neutrophilcytoplasm antibodies in Wegener's granulomatosis are $\stackrel{\odot}{\varnothing}$ not directed against alkaline phosphatase [letter]. Lancet 1987 ; : 1488-9.

18 Goldschmeding $R$, Ten Bokkel Huinink D, von dem Borne AEGKr, The TH. Wegener granulomatosis $ᄋ$ autoantibodies: serological and immunochemical르 characterization of the antigen. Br J Haematol 1987; 66:411. 